\title{
Chloride secretion induced by phorbol dibutyrate and forskolin in the human colonic carcinoma cell line HT-29Cl.19A is regulated by different mechanisms
}

Received: 11 October 1994 / Received after revision: 10 January 1995 / Accepted: 7 February 1995

\begin{abstract}
The human colonic carcinoma cell line HT29cl.19A responds to the protein kinase $\mathrm{C}$ activator PDB (4- $\beta$-phorbol 12,13-dibutyrate), as it does to forskolin (an activator of adenylyl cyclase), with a secretory response when the cells are grown on filters and studied at $36^{\circ} \mathrm{C}$. Previously, we showed that when cells were grown on Petri dishes and studied at about $25^{\circ} \mathrm{C}$ with the cell-attached patch-clamp technique, forskolin, but not PDB, could activate 8-pS chloride channels (cystic fibrosis transmembrane conductance regulator, CFTR, channels). The present work was carried out to study this discrepancy. Experiments in Ussing chambers, at different temperatures, showed that the responses to PDB and forskolin differ in their temperature sensitivity. This was also found following conventional microelectrode and Ussing chamber studies with nystatin-permeabilized epithelial layers carried out at $25^{\circ} \mathrm{C}$ and at $36^{\circ} \mathrm{C}$. Pre-incubation with the microtubular disruptive agents nocodazole or colcemid did not affect the response to PDB or forskolin, suggesting that chloride secretion induced by these agonists in these cells is independent of the microtubular structure. Pre-incubation with brefeldin A strongly inhibited the response to $\mathrm{PDB}$, but the response to forskolin was hardly affected. The differing effect of temperature and brefeldin A on the responses to forskolin and PDB may be due to the activation of two distinct mechanisms by protein kinases $\mathrm{A}$ and $\mathrm{C}$.
\end{abstract}

Key words HT-29cl.19A - Human colon cell line . Temperature $\cdot$ Brefeldin A. Nocodazole $\cdot$ Phorbol ester · PDB $\cdot$ Forskolin $\cdot$ Nystatin $\cdot$ CFTR

R. B. Bajnath $(\triangle) \cdot$ K. Dekker $\cdot$ J. A. Groot Institute of Neurobiology, University of Amsterdam, Faculty of Biology, Kruislaan 320, 1098 SM Amsterdam, The Netherlands

H. R. De Jonge

Department of Biochemistry, Erasmus University, Rotterdam, The Netherlands

\section{Introduction}

Transepithelial chloride secretion in epithelial cells is critically dependent on the activation of chloride channels in the apical membrane. The most prominent chloride channel in salt-secreting epithelia appears to be the product of the CF-gene called the cystic fibrosis transmembrane conductance regulator (CFTR), which is regulated principally by adenosine $3^{\prime}-5^{\prime}$-cyclic monophosphate (cAMP).

From studies with CFPAC cells and human airway epithelial cells it has been suggested that activation of CFTR by cAMP-dependent protein kinase (PKA) regulates plasma membrane recycling via inhibition of endocytosis $[7,20]$ and stimulation of exocytosis. A similar observation has been reported for the T-84 colonic carcinoma cell line, where stimulation with forskolin was found to inhibit the endocytosis of fluidphase markers [6] and to stimulate vesicle migration to the plasma membrane [21].

Whereas much attention has been paid to the regulation of CFTR by PKA, studies regarding the mechanism by which protein kinase $\mathrm{C}$ (PKC) stimulates chloride secretion are very scarce. In previous studies, using the conventional microelectrode technique applied to confluent and filter-grown monolayers of HT-29cl.19A cells studied at $36^{\circ} \mathrm{C}$ in an Ussing-type chamber, we found that addition of $4-\beta$-phorbol 12,13dibutyrate (PDB) or forskolin caused an increase in the chloride conductance of the apical membrane [2,3]. When forskolin and PDB were added after each other, they acted synergistically on apical membrane conductance [4]. With the cell-attached patch-clamp technique performed at $25^{\circ} \mathrm{C}$ on Petri-dish-grown cells, we found that forskolin activated the CFTR chloride channel. Interestingly, a larger number of activated CFTR chloride channels could be observed when PDB was added after forskolin or when forskolin was added after PDB [5]. This may explain the potentiating effect of PDB, as observed in the microelectrode studies. 
However, when PDB was added alone, no CFTR chloride channel activity could be observed. This was in strong contrast to the PDB-induced effects observed using microelectrodes in Ussing chamber studies. Differences between the microelectrode studies and the patch-clamp studies were such that the latter were performed at about $25^{\circ} \mathrm{C}$ and with cells grown in Petri dishes. So, the different results in patch-clamp and microelectrode studies could be due to growth conditions or to the experimental temperature. In the present study we have attempted to discriminate between these possibilities and we have found that the temperature sensitivity of the PDB response between $20^{\circ} \mathrm{C}$ and $30^{\circ} \mathrm{C}$ was larger than that of the forskolin response, so that at about $25^{\circ} \mathrm{C}$ PDB appeared to be almost without effect on the transepithelial potential $\left(V_{t}\right)$ and intracellular potential $\left(V_{\mathrm{a}}\right)$.

Microtubules are thought to play a role in protein transport and incorporation and withdrawal of proteins from the membrane. By analogy with the postulated effects of PKA mentioned above, it might be that PKC acts by stimulating incorporation of chloride channels into the plasma membrane. Therefore, we studied the influence of substances known to interfere with the microtubules. Although microtubular-disruptive agents, e.g. nocodazole and colcemid, appeared to interfere with the basal secretory state of the cells, we could not find evidence supporting a major role of the microtubules in activation by PDB or forskolin of the CFTR chloride channel in the HT-29cl.19A cell type. In contrast, brefeldin $\mathrm{A}$, a fungal metabolite known to block transport of newly synthesized proteins out of the endoplasmic reticulum, suppressed the effect of PDB on the chloride conductance, but pre-incubation with brefeldin A appeared to be without effect on the characteristic ability of forskolin to increase the chloride conductance.

\section{Materials and methods}

Cell culture

HT-29cl.19A cells [2] (passage nos. 20-27) were grown on 25- $\mathrm{mm}$ diameter permeable Falcon filters (Becton Dickinson Labware, N.J., USA) to confluency, which was reached 7 days after seeding; cells were used when they were 10-19 days old. In previous studies no agemrelated differences of the response to forskolin or PDB of these cells were found. Maintenance and subculturing of the cells were carried out as described previously [2].

\section{Microelectrode studies}

For microelectrode experiments, confluent monolayers were mounted horizontally in a small Ussing-type chamber, leaving a oblong area of $0.35 \mathrm{~cm}^{2}$. The upper (apical) and lower (basolateral) compartments were continuously perfused (polystaltic pump, Buchler Instruments, Fort Lee, N.J., USA) with solutions maintained at the desired temperatures (see below) and gassed with $5 \%$ $\mathrm{CO}_{2} / 95 \% \mathrm{O}_{2} . V_{\mathrm{t}}$ was measured with Ringer/agar bridges, which were connected to $\mathrm{Ag}-\mathrm{AgCl}$ electrodes. $V_{\mathrm{a}}$ was measured using glass microelectrodes filled with $0.5 \mathrm{~mol} / 1 \mathrm{KCl}$ which were connected to a high input impedance amplifier (World Precision Instruments, New Haven, Conn., USA). All measurements were performed under open-circuit conditions and the apical solution was used as the reference for transepithelial and intracellular measurements. The effect of added chemicals was studied during simultaneous recordings of $V_{\mathrm{a}}$ and $V_{\mathrm{t}}$.

To calculate resistances, bipolar current pulses of $1 \mathrm{~s}$ duration $( \pm 10 \mu \mathrm{A}$ and $\pm 50 \mu \mathrm{A})$ were injected via $\mathrm{Ag}-\mathrm{AgCl}$ electrodes located in the walls of the upper and lower compartments. From the voltage deflections of $V_{\mathrm{a}}$ and $V_{\mathrm{t}}$ induced by these current pulses, the transepithelial resistance $\left(R_{\mathrm{t}}\right)$ and the fractional resistance of the apical membrane ( $\mathrm{f} R_{\mathrm{a}}=R_{\mathrm{a}} /\left(R_{\mathrm{a}}+R_{\mathrm{b}}\right)$ were calculated. Corrections for solution resistance and for the potential offset of the electrodes were made by measuring the potential difference and currentinduced voltage deflections between the electrodes before mounting and after removal of the filter. The microelectrodes had tip resistances of between $100 \mathrm{M} \Omega$ and $200 \mathrm{M} \Omega$ and the tip potentials were about $-2 \mathrm{mV}$.

\section{Temperature}

Ringer's solutions were brought to the desired temperatures by a heated waterbath and were maintained at these temperatures during flow through water-jacketed tubes and reservoirs. The temperature of the Ringer's solution in the experimental chamber was continuously monitored using a digital thermometer.

\section{Solutions}

Experiments were carried out with a standard Ringer solution of the following composition (in mmol/l): $\mathrm{NaCl} \mathrm{117.5,} \mathrm{KCl} 5.7$, $\mathrm{NaHCO}_{3} 25.0, \mathrm{NaH}_{2} \mathrm{PO}_{4} 1.2, \mathrm{CaCl}_{2} 2.5, \mathrm{MgSO}_{4} 1.2$, glucose 27.8 $(\mathrm{pH} 7.4)$. Chloride-free solutions were prepared by replacing all $\mathrm{NaCl}$, except for $0.1 \mathrm{mmol} / 1$, by $\mathrm{Na}$ gluconate.

Short-circuit current $\left(I_{\mathrm{sc}}\right)$ measurements with nystatin-treated monolayers

For measurements of chloride current, monolayers of HT-29cl.19A cells were grown on permeable polycarbonate filters $(6.4 \mathrm{~mm}$ diameter, Transwell, Costar). HT-29cl.19A cells grown on these filters respond similarly to forskolin or $\mathrm{PDB}$, as compared to cells grown on Falcon filters. The exposed area of the filter was $0.35 \mathrm{~cm}^{2}$. The basolateral side of the filter was bathed in a buffer solution containing (in mmol/1): $\mathrm{NaCl} 105, \mathrm{KCl} 4.7, \mathrm{CaCl}_{2} 1.3, \mathrm{MgCl}_{2} 1.0$, $\mathrm{NaHCO}_{3}$ 20.2, $\mathrm{Na}_{2} \mathrm{HPO}_{4}$ 0.33, 4-(2-hydroxyethyl) 1-piperazineethanesulphonic acid (HEPES) 10, glucose 10. The buffer solution at the apical side had the same composition, except for $\mathrm{NaCl}$ and $\mathrm{KCl}$ which were replaced by equal amounts of $\mathrm{Na}$ gluconate and $\mathrm{K}$ gluconate, respectively. Before stimulation with PDB or forskolin, $0.36 \mathrm{~g} / 1$ nystatin was added to the basolateral solution, while $V_{\mathrm{t}}$ was clamped at $0 \mathrm{mV}$.

\section{Chemicals}

All chemicals including forskolin, PDB, colcemid, nocodazole and brefeldin A were purchased from Sigma, St Louis, Mo., USA. Cell culture materials were purchased from GIBCO.

\section{Statistics}

The paired or unpaired $t$-test was used to evaluate statistical significance. 


\section{Results}

The effects of PDB and forskolin on $V_{\mathrm{t}}$ and $R_{\mathrm{t}}$ were compared at different temperatures. Each filter was exposed to only one temperature, and forskolin or PDB (usually followed by PDB or by forskolin, respectively) were applied only once. Figure 1 shows the relative temperature dependency of the PDB- and the forskolin-

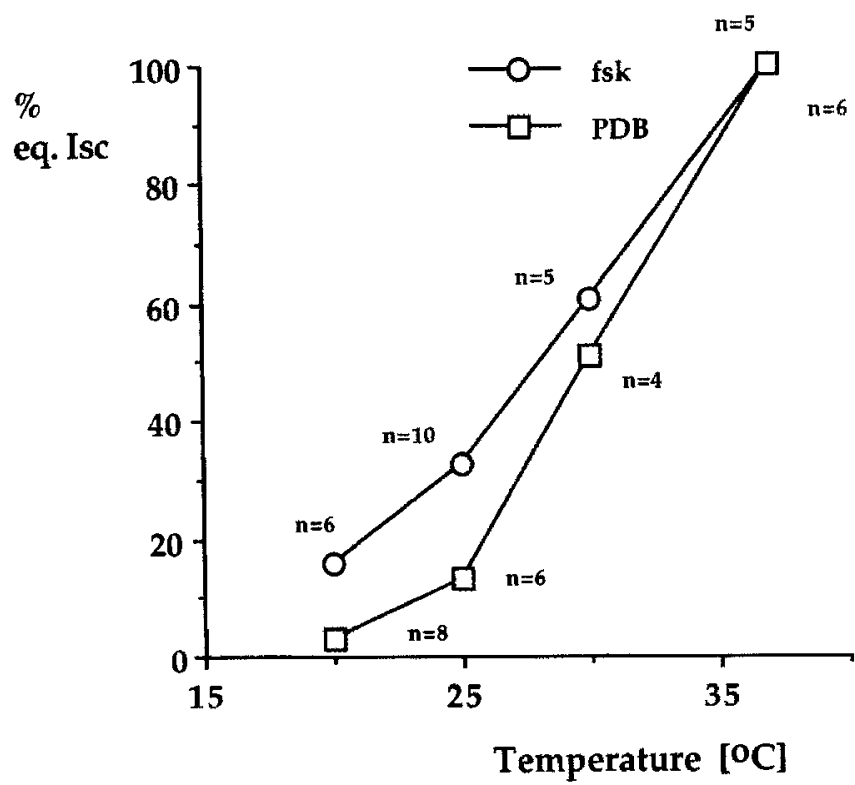

Fig. 1 Plot of relative equivalent short-circuit current (eq. $I_{\mathrm{sc}}$ ) against temperature $\left({ }^{\circ} \mathrm{C}\right)$ induced by application of 4 - $\beta$-phorbol 12,13-dibutyrate $\left(P D B, 10^{-6} \mathrm{M}\right)$ and forskolin $\left(f s k, 10^{-5} \mathrm{M}\right)$. Values represent mean \pm SEM for the number $(n)$ of experiments as indicated at different temperatures. Values of SEM are smaller than the symbols used. Eq. $I_{\mathrm{sc}}$ was calculated from transepithelial potential $\left(V_{\mathrm{t}}\right)$ and the transepithelial resistance $\left(R_{\mathrm{t}}\right)$. The maximal $I_{\mathrm{sc}}$ induced by forskolin or PDB at $36^{\circ} \mathrm{C}$ was $31.3 \pm 6 \mu \mathrm{A} / \mathrm{cm}^{2}$ and $21.2 \pm 5 \mu \mathrm{A} / \mathrm{cm}^{2}$, respectively. These values are not significantly different $(P>0.1$, unpaired $t$-test $)$ induced equivalent $I_{\mathrm{sc}}$ (eq. $I_{\mathrm{sc}}$ ). The effect of PDB at $25^{\circ} \mathrm{C}$ was only $13 \%$ of its effect at $36^{\circ} \mathrm{C}$, whereas the effect of forskolin at $25^{\circ} \mathrm{C}$ was about $33 \%$ of its effect at $36^{\circ} \mathrm{C}$. The effect of forskolin increased monotonously with temperature. In contrast, between $20^{\circ} \mathrm{C}$ and $25^{\circ} \mathrm{C}$ the effect of PDB was rather small, but increased rapidly as the temperature was raised to $36^{\circ} \mathrm{C}$. The time needed to reach the maximal change (see Table 1) was shorter for forskolin, except at $20^{\circ} \mathrm{C}$. At this temperature, the time course of the response to both secretagogues was nearly the same, but the effect of forskolin was much larger.

Table 1 shows the changes in eq. $I_{\mathrm{sc}}$ induced by the secretagogues alone and in combination. PDB addition after forskolin induced a larger change than when added alone. The effect of addition of forskolin after PDB was strongly reduced at $36{ }^{\circ} \mathrm{C}$, due to the described effect of PDB on the basolateral $\mathrm{K}^{+}$conductance [3]. At the other temperatures, the effect on eq. $I_{\text {sc }}$ of addition of forskolin after PDB was not different to the effect of when it was added alone.

$I_{\mathrm{sc}}$ measurements in nystatin-treated monolayers at $25^{\circ} \mathrm{C}$ and at $36^{\circ} \mathrm{C}$

$I_{\mathrm{sc}}$ is not only dependent on the apical membrane chloride conductance, but also on the basolateral $\mathrm{K}^{+}$conductance and the $\mathrm{Na} / \mathrm{K} / \mathrm{Cl}$-cotransporter and $\mathrm{Na} / \mathrm{K}$ pump. To test the possibility that the difference in temperature sensitivity of the PDB and forskolin effects are due to differences in basolateral membrane characteristics, we permeabilized the basolateral membrane with nystatin. Monolayers were voltage-clamped at $0 \mathrm{mV}$ and exposed to nystatin on the basolateral side in the presence of a chloride concentration gradient at $25^{\circ} \mathrm{C}$ or at $36^{\circ} \mathrm{C}$. Addition of PDB at $25^{\circ} \mathrm{C}$ increased $I_{\mathrm{sc}}$ by only $1.2 \pm 0.6 \mu \mathrm{A} / \mathrm{cm}^{2}$ (mean \pm SEM, $n=9$ ).
Table 1 Comparison of the effects of forskolin and $4-\beta$ phorbol 12,13-dibutyrate (PDB) at different temperatures on the equivalent short-circuit current (change of eq. $I_{\mathrm{sc}}$ in $\mu \mathrm{A} / \mathrm{cm}^{2}$ ). Values were taken at the maximum of the response, which was reached at the time indicated. All values are mean $\pm \mathrm{SEM}$. Number of experiments in parentheses

\begin{tabular}{|c|c|c|c|c|}
\hline \multirow[t]{2}{*}{ Temperature $\left({ }^{\circ} \mathrm{C}\right)$} & \multicolumn{4}{|c|}{ Change in eq. $I_{\mathrm{sc}}\left(\mu \mathrm{A} / \mathrm{cm}^{2}\right)$ under the following conditions: } \\
\hline & Forskolin & PDB & $\begin{array}{l}\text { PDB after } \\
\text { forskolin }\end{array}$ & $\begin{array}{l}\text { Forskolin } \\
\text { after PDB }\end{array}$ \\
\hline 20 & $5.0 \pm 1.6(6)$ & $2.0 \pm 0.7(8)$ & $4 \pm 1(6) \mathrm{a}$ & $4.7 \pm 1.2(8)$ \\
\hline $\begin{array}{l}\text { Time to maximum } \\
\text { (min) }\end{array}$ & $38 \pm 4$ & $39 \pm 4$ & $30 \pm 1.4$ & $19 \pm 1.8$ \\
\hline 25 & $10 \pm 2(10)$ & $2.8 \pm 1.2(6)$ & $15 \pm 5(8)^{\mathrm{a}}$ & $12 \pm 5(6)$ \\
\hline $\begin{array}{l}\text { Time to top } \\
\text { (min) }\end{array}$ & $5.4 \pm 0.4$ & $15 \pm 0.6$ & $9.4 \pm 0.4$ & $4.0 \pm 0.3$ \\
\hline 30 & $17 \pm 6(5)$ & $11 \pm 1(4)$ & nd & nd \\
\hline $\begin{array}{l}\text { Time to top } \\
\text { (min) }\end{array}$ & $3.0 \pm 0.3$ & $8.0 \pm 0.3$ & & \\
\hline 36 & $31 \pm 6(5)$ & $21 \pm 5(6)$ & $39 \pm 10(5)$ & $13 \pm 1(5)^{b}$ \\
\hline $\begin{array}{l}\text { Time to top } \\
\text { (min) }\end{array}$ & $3.0 \pm 0.2$ & $6.0 \pm 0.5$ & $2.2 \pm 0.1$ & $1.7 \pm 0.3$ \\
\hline
\end{tabular}

a Different from effect of PDB alone $P<0.05$,

b Different from effect of forskolin alone $P<0.05$ 
Consecutive stimulation with forskolin increased $I_{\mathrm{sc}}$ by $54.3 \pm 4.1 \mu \mathrm{A} / \mathrm{cm}^{2}$ (mean \pm SEM, $n=9$ ), indicating a chloride flux from the basolateral to the apical side. Forskolin, when added alone, increased $I_{\mathrm{sc}}$ by $23.2 \pm$ $4.1 \mu \mathrm{A} / \mathrm{cm}^{2}(n=6)$. In two experiments at $36^{\circ} \mathrm{C}, \mathrm{PDB}$ increased $I_{\mathrm{sc}}$ by $45 \mu \mathrm{A} / \mathrm{cm}^{2}$ and by $37 \mu \mathrm{A} / \mathrm{cm}^{2}$, respectively. Application of forskolin alone increased $I_{\mathrm{sc}}$ by $87 \pm 5 \mu \mathrm{A} / \mathrm{cm}^{2}(n=7)$ at $36^{\circ} \mathrm{C}$. The PDB- or forskolininduced $I_{\mathrm{sc}}$ was not inhibited by bumetanide or barium at the basolateral side, indicating that nystatin effectively permeabilized the basolateral membranes. Thus, even when effects via the basolateral membrane were ruled out, PDB appeared to have a negligible effect at $25^{\circ} \mathrm{C}$, but when forskolin was applied after PDB, the increase of the apical chloride conductance was potentiated as in patch-clamp experiments carried out at $25^{\circ} \mathrm{C}$. The nystatin experiments suggest that the absence of synergism of forskolin application after that of PDB on the eq. $I_{\mathrm{sc}}$ at $20^{\circ} \mathrm{C}$ and $25^{\circ} \mathrm{C}$, as shown in Table 1, may be due to the limited conductance of the basolateral membrane.

\section{Microelectrode experiments at $25^{\circ} \mathrm{C}$ or $36^{\circ} \mathrm{C}$}

Figure $2 \mathrm{~A}, \mathrm{~B}$ shows a comparison between the effects of PDB and forskolin when added separately and when added consecutively on $V_{\mathrm{a}}$ and $\mathrm{f} R_{\mathrm{a}}$ at $25^{\circ} \mathrm{C}$ and at $36^{\circ} \mathrm{C}$. At $25^{\circ} \mathrm{C}$, PDB had no significant $(P>0.1)$ effect on $V_{\mathrm{a}}$ (Fig. $2 \mathrm{~A}$ ) or $\mathrm{f} R_{\mathrm{a}}$ (Fig. $2 \mathrm{~B}$ ), but at $36^{\circ} \mathrm{C} \mathrm{PDB}$ induced a depolarization of $V_{\mathrm{a}}$ and a decrease of $\mathrm{f} R_{\mathrm{a}}$ of a magnitude comparable to results reported previously [3]. In contrast, forskolin induced a depolarization of $V_{\mathrm{a}}$ of similar magnitude at both temperatures (Fig. 2A). The decrease of $\mathrm{f} R_{\mathrm{a}}$ at $36^{\circ} \mathrm{C}$ was significantly $(P<0.001)$ larger than at $25^{\circ} \mathrm{C}$. PDB addition after forskolin decreased $\mathrm{f} R_{\mathrm{a}}$ in every experiment at both temperatures. Addition of forskolin after PDB induced a further depolarization of $V_{\mathrm{a}}$ and a further decrease of $\mathrm{f} R_{\mathrm{a}}$.

The different temperature sensitivity of the responses to PDB and to forskolin suggests that these agonists exert their effects via activation of different mechanisms. One possibility may be that PKC acts primarily by stimulating the transport and incorporation of channel proteins in the apical membrane and that these channels are opened by spontaneously active PKA. Both membrane incorporation and the number of spontaneously active PKA molecules will be less at lower temperatures and it may be that the smaller amount of endogeneously activated PKA and the smaller number of channels decrease the chance of interaction and activation. To investigate the possible involvement of protein transport as a part of the PDB effect, experiments were carried out with nocodazole and brefeldin $\mathrm{A}$. These agents are known to interfere with membrane protein recruitment processes in some, but not all, cell types $[8,17,18]$.

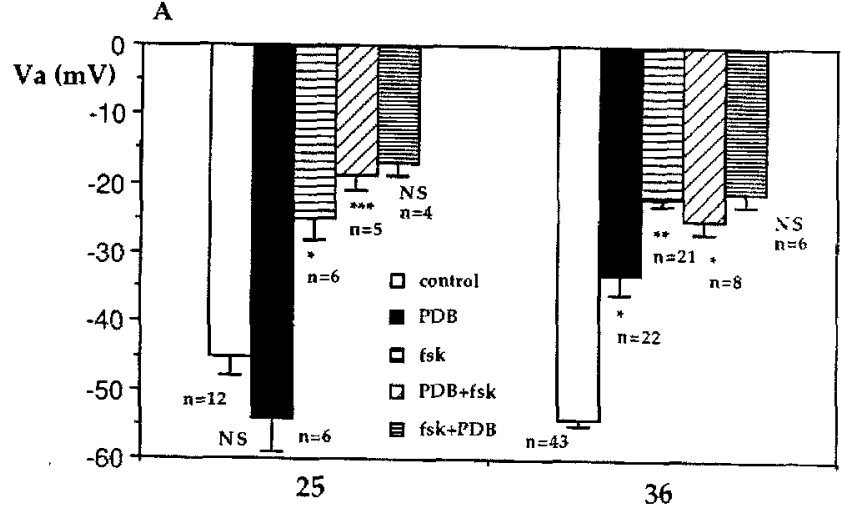

temperature $\left[{ }^{\circ} \mathrm{C}\right]$

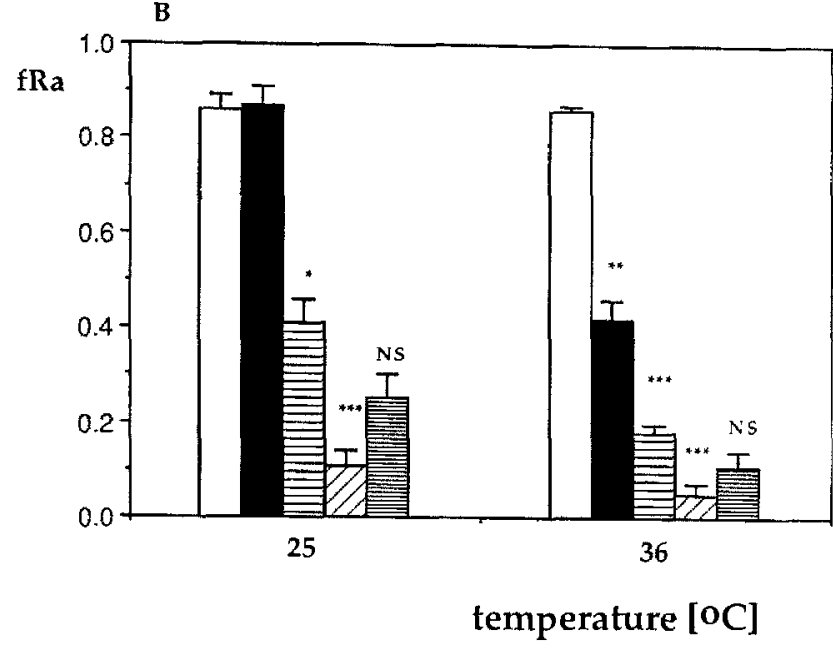

Fig. 2 Membrane potential $\left(V_{\mathrm{a}}\right)(\mathbf{A})$ and fractional resistance of the apical membrane $\left(\mathrm{fR}_{\mathrm{a}}\right)(\mathrm{B})$ showing the effects of $\left(10^{-6} \mathrm{M}\right)$ PDB or $\left(10^{-5} \mathrm{M}\right)$ forskolin separately and when added sequentially at two different temperatures. ${ }^{*} P<0.01,{ }^{* *} P<0.001,{ }^{* * *} P<0.0001$. Values represent mean \pm SEM for $(n)$ experiments

\section{Effect of nocodazole at $36^{\circ} \mathrm{C}$}

Table 2 shows that after incubation with nocodazole for $1-7 \mathrm{~h}(4 \pm 0.3 \mathrm{~h}$, mean $\pm \mathrm{SEM}, n=11)$ one could observe a significant increase of $V_{\mathrm{t}}$, a depolarization of $V_{\mathrm{a}}$ and decrease of $\mathrm{f} R_{\mathrm{a}}$ with respect to control values. As a consequence, eq. $I_{\mathrm{sc}}$ was significantly increased. A plot of $V_{\mathrm{t}}$ against $V_{\mathrm{a}}$ of nocodazole-treated monolayers (not shown) yielded a linear relationship with a slope which was different $(P<0.001)$ from zero, whereas no relationship between $V_{\mathrm{t}}$ and $V_{\mathrm{a}}$ was found in untreated monolayers. This suggests that the larger $V_{\mathrm{t}}$ after nocodazole treatment is related to the depolarization of $V_{a}$. Similar effects were also found when monolayers were pre-incubated with colcemid, another frequently used microtubule-disruptive agent (results not shown).

Table 3 shows a summary of the changes induced by PDB or forskolin in control conditions and after incubation with nocodazole. The PDB- or forskolininduced changes were usually smaller than without pre-treatment with nocodazole, but the membrane 
Table 2 Electrical parameters of the cells under control conditions or after incubation with nocodazole or brefeldin A. $\left(V_{\mathrm{t}}\right.$ transepithelial potential, $V_{\mathrm{a}}$ apical membrane potential, $R_{\mathrm{t}}$ transepithelial resistance, f $R_{\mathrm{a}}$ fractional apical membrane resistance, $N$ number of experiments).Values shown are mean \pm SEM. Mono- layers were treated with either $33 \mu \mathrm{M}$ nocodazole for $1-7 \mathrm{~h}$ or with $1-10 \mu \mathrm{g} / \mathrm{ml}$ brefeldin A for $1-8 \mathrm{~h}$. During experiments the same concentrations of the drugs were present in the apical and the basolateral perfusate

\begin{tabular}{|c|c|c|c|c|c|c|}
\hline \multirow[t]{2}{*}{ Condition } & \multicolumn{6}{|l|}{ Parameter } \\
\hline & $\begin{array}{l}V_{\mathrm{t}} \\
(\mathrm{mV})\end{array}$ & $\begin{array}{l}V_{\mathrm{a}} \\
(\mathrm{mV})\end{array}$ & $\begin{array}{l}R_{\mathrm{t}} \\
\left(\Omega \mathrm{cm}^{2}\right)\end{array}$ & $£ R_{\mathrm{a}}$ & $\begin{array}{l}\text { eq. } I_{\mathrm{sc}} \\
\left(\mu \mathrm{A} / \mathrm{cm}^{2}\right)\end{array}$ & $N$ \\
\hline Control & $0.8 \pm 0.1$ & $-54 \pm 1$ & $150 \pm 9$ & $0.86 \pm 0.01$ & $6 \pm 1$ & 49 \\
\hline Nocodazole & $2.5 \pm 0.5^{* *}$ & $-48 \pm 3^{*}$ & $157 \pm 13$ & $0.62 \pm 0.06^{* *}$ & $17 \pm 4^{* *}$ & 11 \\
\hline Brefeldin A & $0.6 \pm 0.1$ & $-55 \pm 2$ & $171 \pm 14$ & $0.82 \pm 0.02$ & $4 \pm 1$ & 17 \\
\hline
\end{tabular}

$* P<0.01, * * P<0.001$, Unpaired $t$-test

Table 3 Comparison of changes in $V_{\mathrm{a}}, \mathrm{f} R_{\mathrm{a}}$ and $I_{\mathrm{sc}}$ induced by forskolin $(f s k)$ $\left(10^{-5} \mathrm{M}\right)$ or PDB $\left(10^{-6} \mathrm{M}\right)$ under control conditions and after pre-incubation with 33 $\mu \mathrm{M}$ nocodazole for $1-7 \mathrm{~h}$. Values shown are mean \pm SEM. Changes induced by PDB or fsk without or with nocodazole pre-incubation were not significantly different from each other; $P>0.1$, unpaired $t$-test. Data with respect to nocodazole preincubation are from Table 2

\begin{tabular}{lllllllr}
\hline Condition & \multicolumn{2}{l}{ Parameter } & & & \\
\cline { 2 - 8 } & \multicolumn{1}{l}{$\begin{array}{l}V_{\mathrm{a}} \\
(\mathrm{mV})\end{array}$} & $\begin{array}{l}\Delta V_{\mathrm{a}} \\
(\mathrm{mV})\end{array}$ & $\mathrm{f} R_{\mathrm{a}}$ & $\Delta \mathrm{f} R_{\mathrm{a}}$ & $\begin{array}{l}\text { eq. } I_{\mathrm{sc}} \\
\left(\mu \mathrm{A} / \mathrm{cm}^{2}\right)\end{array}$ & $\begin{array}{l}\Delta \mathrm{eq} . I_{\mathrm{sc}} \\
\left(\mu \mathrm{A} / \mathrm{cm}^{2}\right)\end{array}$ & $N$ \\
\hline Control & $-55 \pm 2$ & & $0.85 \pm 0.01$ & & $5 \pm 1$ & & 13 \\
Fsk & $-25 \pm 2$ & $30 \pm 3$ & $0.23 \pm 0.03$ & $0.62 \pm 0.02$ & $34 \pm 3$ & $29 \pm 3$ & 11 \\
PDB & $-32 \pm 3$ & $23 \pm 4$ & $0.41 \pm 0.01$ & $0.44 \pm 0.01$ & $24 \pm 2$ & $19 \pm 2$ & 4 \\
Nocodazole & $-48 \pm 3^{\mathrm{a} *}$ & $7 \pm 4$ & $0.62 \pm 0.06^{\mathrm{a} * *}$ & $0.23 \pm 0.06$ & $17 \pm 4^{\mathrm{a} * *}$ & $12 \pm 4$ & 11 \\
$\begin{array}{l}\text { (1-7 h pre-incubation) }) \\
\text { Nocodazole + Fsk }\end{array}$ & $-26 \pm 5$ & $22 \pm 6$ & $0.18 \pm 0.04$ & $0.44 \pm 0.07$ & $36 \pm 3$ & $19 \pm 5$ & 5 \\
Nocodazole + PDB & $-31 \pm 2$ & $17 \pm 4$ & $0.30 \pm 0.05$ & $0.32 \pm 0.08$ & $35 \pm 6$ & $18 \pm 7$ & 6 \\
\hline
\end{tabular}

* $P<0.01, * * P<0.001$ unpaired $t$-test

${ }^{\text {a }}$ Comparison with control values potential, the fractional resistance and eq. $I_{\mathrm{sc}}$ were not significantly different.

\section{Effect of brefeldin $\mathrm{A}$ at $36^{\circ} \mathrm{C}$}

Incubation for $1-8 \mathrm{~h}(4 \pm 0.7 \mathrm{~h}$, mean $\pm \mathrm{SEM}, n=17)$ of monolayers with brefeldin A $(1-10 \mu \mathrm{g} / \mathrm{ml})$ had no effect on basal electrical parameters (see Table 2). The effects of forskolin on $V_{\mathrm{a}}, \mathrm{f} R_{\mathrm{a}}$ or $I_{\mathrm{sc}}$ after pre-incubations with brefeldin A (Fig. 3A-C) were not significantly affected as compared with controls. In contrast, all PDB-induced changes were significantly smaller, although the responses were qualitatively unaltered. Pre-incubation with brefeldin A strongly suppressed the PDB-induced increase of $I_{\mathrm{sc}}$ after treatment with forskolin (Fig. 4).

Prolonged incubations (22-24 h) of monolayers with brefeldin A $(1 \mu \mathrm{g} / \mathrm{ml})$ further reduced the effect of PDB on $V_{\mathrm{a}}$ (Fig. 5), but, in addition, strongly reduced the $R_{\mathrm{t}}$ of the monolayer, making calculations of $\mathrm{f} R_{\mathrm{a}}$ and $I_{\mathrm{sc}}$ rather uncertain. In two experiments carried out on separate filters incubated for $21 \mathrm{~h}$ with brefeldin A, forskolin induced a depolarization of $V_{\mathrm{a}}$ by $35 \mathrm{mV}$ from a membrane potential of $-47 \mathrm{mV}$ and by $31 \mathrm{mV}$ from a membrane potential of $-43 \mathrm{mV}$, respectively. We tested whether the depolarization of the apical mem- brane induced by forskolin after this long treatment with brefeldin $\mathrm{A}$ was due to the opening of chloride channels by lowering the chloride concentration at the apical side from $127 \mathrm{mmol} / 1$ to $0.1 \mathrm{mmol} / 1$. This induced a further depolarization of $V_{\mathrm{a}}$ by $32 \mathrm{mV}$ and by $38 \mathrm{mV}$, respectively (after correction by $-9.5 \mathrm{mV}$ for the liquid junction potential across the apical salt bridge). These changes are of similar magnitude to those without brefeldin A treatment [3]. This differs from the absence of effect of apical chloride replacement in the presence of PDB after brefeldin A pre-incubation (Fig. 5). Figure 5 also shows that subsequent addition of forskolin reversed $V_{\mathrm{a}}$ to $+27 \mathrm{mV}$. The absence of an effect of apical chloride replacement after PDB and brefeldin A treatment contrasts with the effect when the cells were not treated with brefeldin A. In two experiments, PDB depolarized $V_{\mathrm{a}}$ by $21 \mathrm{mV}$ from a membrane potential of $51 \mathrm{mV}$ and by $20 \mathrm{mV}$ from a membrane potential of $65 \mathrm{mV}$. Subsequent lowering of the apical chloride concentration further depolarized $V_{\mathrm{a}}$ by $15 \mathrm{mV}$ and by $13 \mathrm{mV}$ (corrected for the liquid junction potential). From these experiments it can be deduced that the PDB-induced depolarization after brefeldin A treatment was not due to activation of apical chloride channels. The cause of the PDBinduced depolarization after prolonged brefeldin A incubation remains to be investigated. 
A
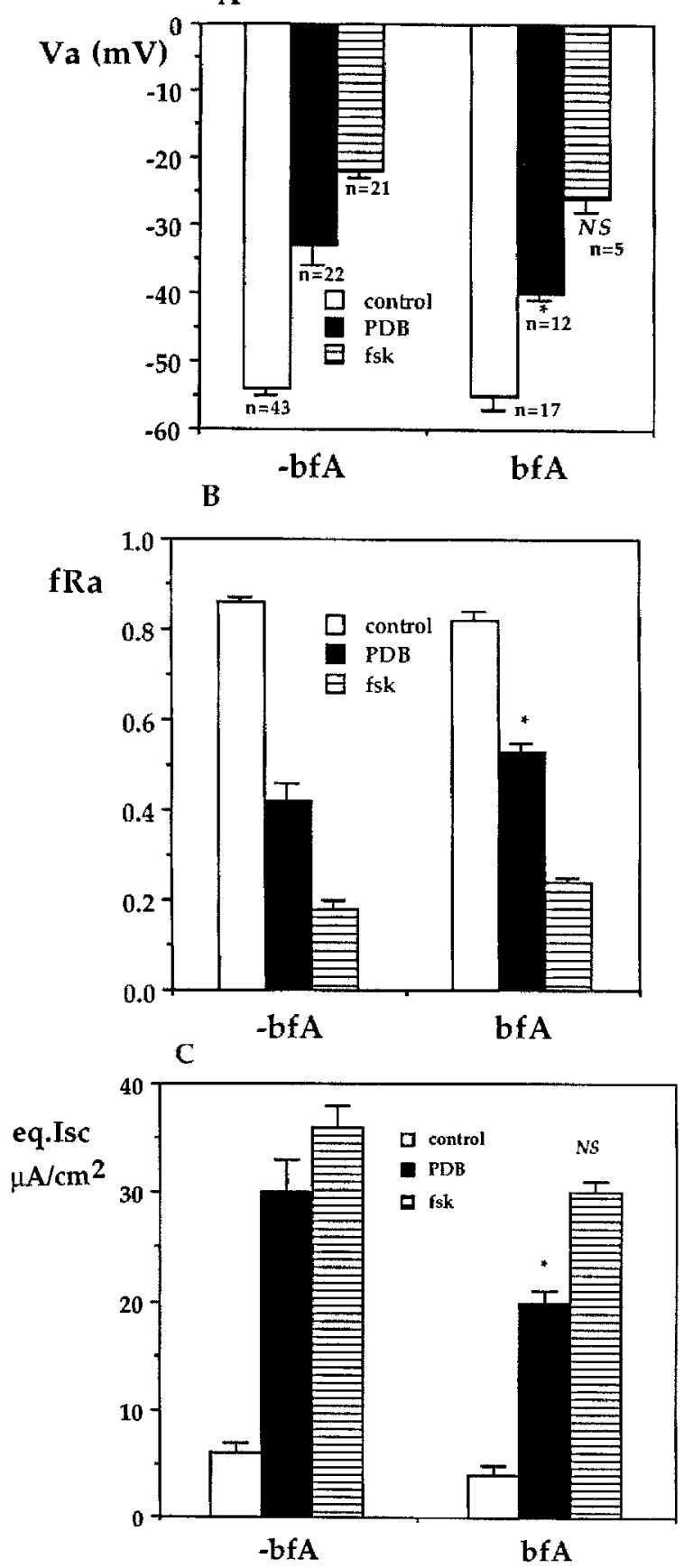

Fig. 3 Effect of pre-incubation with brefeldin A ( $b f A, 1 \mu \mathrm{g} / \mathrm{ml})$ on the (PDB-and the forskolin-induced changes of $V_{\mathrm{a}}(\mathbf{A}) \mathrm{f} R \mathrm{a}(\mathbf{B})$ and eq. $I_{\mathrm{sc}}(\mathbf{C}) * P<0.02$, NS = not significantly different from values without brefeldin A pre-incubation. Values represent mean \pm SEM for $(n)$ experiments

\section{Discussion}

The present work was carried out as an attempt to find an explanation for the discrepancy of the PDB response between microelectrode studies at $36^{\circ} \mathrm{C}$ with filtergrown monolayers and patch-clamp studies with cells grown in Petri dishes and studied at $25^{\circ} \mathrm{C}$. The main findings are that forskolin- and PDB-induced chloride

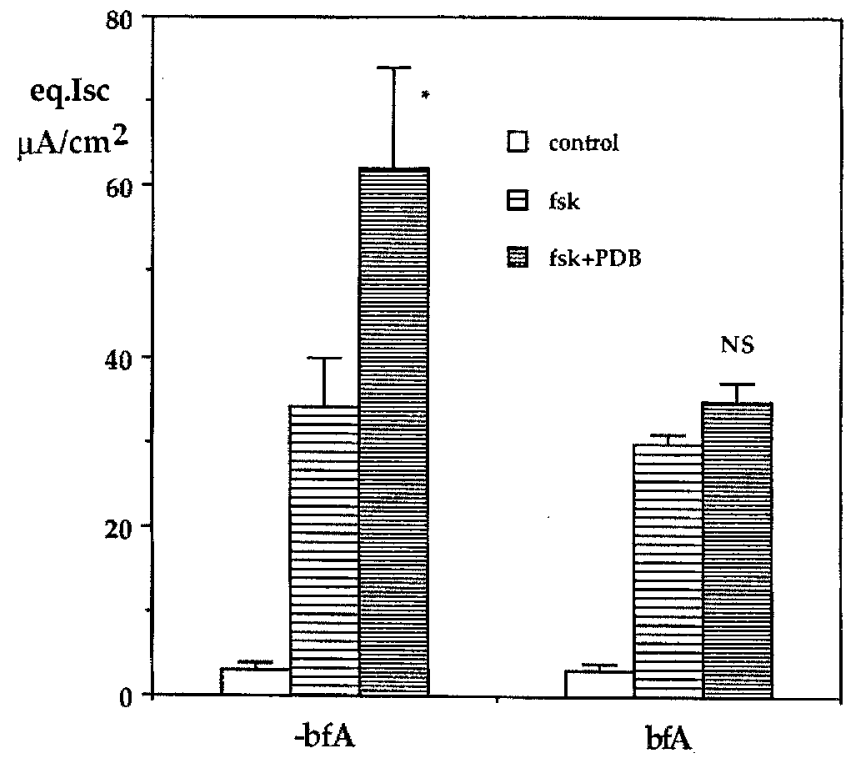

Fig. 4 Inhibitory effect of brefeldin A $(b f A, 1 \mu \mathrm{g} / \mathrm{ml})$ pre-incubation $(1-7 \mathrm{~h})$ on the increase of eq. $I_{\mathrm{sc}}$ evoked by PDB when added after stimulation with forskolin. $* P<0.05$, NS $=$ not significantly different from values in the presence of forskolin alone. Values represent mean \pm SEM for 5 experiments in the absence of brefeldin $\mathrm{A}$ and for 4 after pre-incubation with brefeldin $\mathrm{A}$

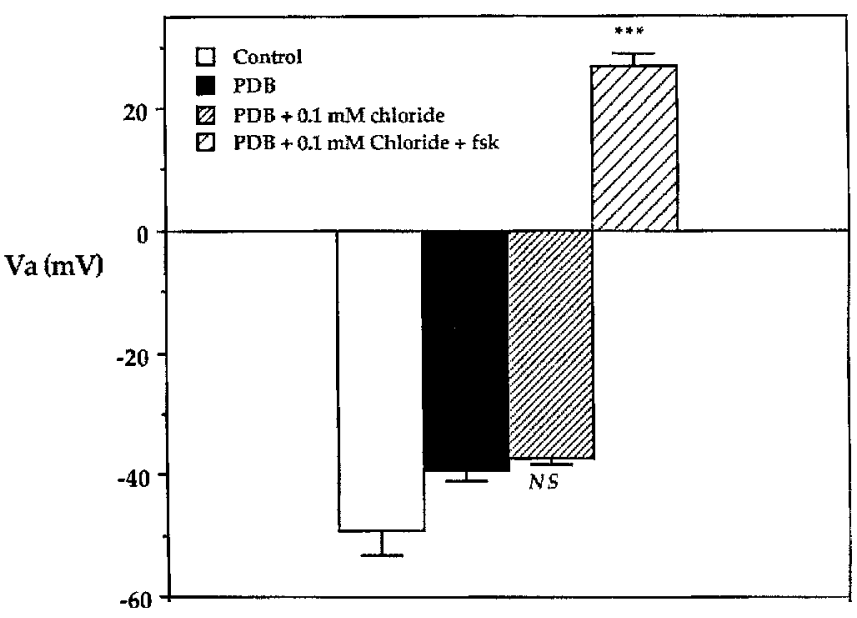

Fig. 5 Membrane potentials after prolonged (22-24 h) incubation with brefeldin A without (control) and after addition of $10^{-6} \mathrm{M}$ PDB. The third bar shows the lack of effect of lowering the chloride concentration to $0.1 \mathrm{mmol} / 1$ in the apical compartment (chloride replaced by gluconate) in the presence of PDB and the large depolarization (fourth bar) after addition of $10^{-5} \mathrm{M}$ forskolin. $* * * P<0.0001, \mathrm{NS}=$ not significantly different from values in the presence of control solution. Values represent mean \pm SEM for 6 experiments

secretion show different temperature sensitivity and a different sensitivity to brefeldin A.

\section{Effect of temperature}

Eq. $I_{\mathrm{sc}}$ at $25^{\circ} \mathrm{C}$ or $36^{\circ} \mathrm{C}$ with nystatin in the basolateral compartment showed that forskolin can increase 
$I_{\mathrm{sc}}$ at both temperatures. Nystatin selectively eliminates the contribution of the basolateral membrane to the transcellular resistance, therefore the measured current across the monolayer reflects the chloride current flowing through activated apical chloride channels, driven by the experimental chloride concentration gradient, from the serosal to the mucosal side [1]. In contrast, PDB failed to increase the current at $25^{\circ} \mathrm{C}$, but potentiated the forskolin-induced $I_{\mathrm{sc}}$. As expected from microelectrode studies, at $36{ }^{\circ} \mathrm{C}$ PDB increased $I_{\mathrm{sc}}$ in the nystatin experiments as well. The almost complete absence of chloride current at $25^{\circ} \mathrm{C}$ after stimulation with PDB and the large increase of the current in the presence of PDB plus forskolin fully agree with our earlier findings from cell-attached patch-clamp studies and indicate that, at the lower temperature, application of PDB does not lead to activation of chloride channels in filter-grown cells. This is similar for cells grown in Petri dishes and indicates that the absence of chloride channel activation by PDB in the patch-clamp studies was not due to different growth conditions. This is in agreement with the results of the microelectrode studies performed at $25^{\circ} \mathrm{C}$ (Fig. 2A,B). It is hard to explain the changes in eq. $I_{\mathrm{sc}}$ measured at $20-25^{\circ} \mathrm{C}$ (Fig. 1, Table 1) as being due to PDB-induced chloride currents, because PDB did not change $V_{\mathrm{a}}$ at $25^{\circ} \mathrm{C}$ and had hardly any effect on the chloride conductance in the nystatin experiments. The nature of this current remains to be studied.

Activation of the eq. $I_{\mathrm{sc}}$ by forskolin shows a more or less linear temperature dependency, with still appreciable activation at lower temperatures. Similarly, in T84 cells, the mechanism appears not to be very temperature sensitive, as Denning et al. [9] have shown appreciable activation even at $5^{\circ} \mathrm{C}$.

\section{Effect of cytoskeletal disruptive agents}

To test a possible role of vesicle insertion in the mechanism of CFTR activation in HT-29cl.19A cells, the cytoskeletal architecture was perturbed by the microtubular agonists nocodazole or colcemid. It has been reported that, by depolymerizing the microtubuli, the incorporation of vesicles in the apical membrane can be inhibitied in some, but not all, cells $[17,18]$.

In the HT-29cl.19A cells these agents appeared to have an effect on the apical membrane conductance. The decrease of $\mathrm{f} R_{\mathrm{a}}$, the depolarization of $V_{\mathrm{a}}$ and the increase of $V_{\mathrm{t}}$ and of eq. $I_{\mathrm{sc}}$ after treatment with nocodazole can be interpreted as a consequence of a larger number of basally active chloride channels in the apical membrane. This hypothesis and the possible reason for increased chloride channel activity have not yet been studied.

In contrast to our observations that the electrophysiological effects of secretagogues were not inhibited, Fuller et al. [11] reported that, in T-84 cells, pre-incubation with nocodazole or colchicine partially inhibited the forskolin-induced $\left.{ }^{125} \mathrm{I}^{-}\right]$efflux. The T-84 cells were used after 3-5 days culture on plastic plates; it may be that this made the cells less polarized than the HT-29cl.19A cells used in the present study. As it appears that the inhibition of targeted transport by nocodazole is more effective in less polarized cells $[12,22]$, the degree of polarization may account for the differing sensitivity.

\section{Experiments with brefeldin A}

Brefeldin A has been reported to block the vesicular transport of proteins between the endoplasmic reticulum and the Golgi apparatus [14, 15], thus preventing the transport of newly synthesized proteins and membrane transporters [8] to the plasma membrane.

In this study we focused on the difference between the PDB- and the forskolin-induced effects. We grouped the brefeldin A experiments together because all incubation periods were present in the forskolin as well as in the PDB experiments. Brefeldin A reduced the effect of PDB when added alone and after forskolin. This inhibition required a pre-incubation of at least $1 \mathrm{~h}$ and the inhibition became more pronounced after prolonged incubations, leading to a total absence of chloride channel activation by PDB. In contrast, brefeldin A had no significant effect on the forskolin-evoked depolarizations. We conclude that, in this laboratory, the activation of apical chloride channels by forskolin was not strongly affected by prolonged $(22-24 \mathrm{~h})$ or short-term $(1-7 \mathrm{~h})$ incubations with brefeldin $\mathrm{A}$. This is in contrast with a recent publication [16], in which it was shown that a 12-h incubation with brefeldin A inhibits the cAMP-induced $I_{s c}$ in the same clone. In our laboratory, prolonged incubation with brefeldin A strongly reduced the monolayer $R_{t}$, making it impossible to measure $I_{\mathrm{sc}}$. However, even then, forskolin was still able to induce a large depolarization of $V_{\mathrm{a}}$

Our results suggest that cAMP-induced activation of chloride secretion need not be fully dependent on the translocation of chloride channels from a cytoplasmic pool into the plasma membrane. This postulate is in agreement with results from immunofluorescence observation by Prince et al. [19] and Morris et al. [16]. These authors showed that the CFTR chloride channel was already present in the plasma membrane of T-84 cells and HT-29cl.19A cells under resting conditions and that stimulation with cAMP agonists did not further increase the amount of fluorescence in T-84 cells. Very recently, Huflejt et al. [13] showed that forskolin hardly increased GAG (Glycosaminoglycan) secretion in T-84 cells, suggesting that exocytosis is not the most important part in the sequence of forskolininduced chloride secretion.

To explain our finding that PDB can activate chloride channels at higher but not at lower temperatures, 
we postulate that activation of PKC induces an increase in the number of channels in the membrane. This will increase the probability that these channels are activated by endogenously active PKA. If this postulate is correct, the effect of PDB would be dependent on the endogeneous activity of PKA, which is dependent on the temperature and of course on the cytoplasmic level of cAMP. Such a mechanism may explain findings reported in literature of increased secretion without increased cAMP levels [10]. The synergistic effect of PDB and forskolin on the apical membrane conductance $([4,5]$ this report) may be explained by postulating that: (1) PKC can increase the number of chloride channels in the membrane; and (2) the increased number of channels in the membrane can be activated by the much more active PKA. This will lead to a much larger apical membrane conductance than following treatment with forskolin or PDB alone. The reason for the lack of chloride current when PDB was added alone at the lower temperature may be that the endogenous PKA activity at these temperatures is too low to activate the channels in the apical membrane.

Acknowledgement This work was supported by the Dutch organization of Scientific Research (NWO). We thank Drs. Augeron and Laboisse for donation of the HT29cl.19A.

\section{References}

1. Anderson MP, Welsh MJ (1991) Calcium and cAMP activate different chloride channels in the apical membrane of normal and cystic fibrosis epithelia. Proc Natl Acad Sci USA 88: 6003-6007

2. Bajnath RB, Augeron C, Laboisse CL, Bijman J, De Jonge HR, Groot JA (1991) Electrophysiological studies of forskolininduced changes in ion transport in the human colon carcinoma cell line HT-29cl.19A: lack of evidence for a cAMP-activated basolateral $\mathrm{K}^{+}$conductance. J Membr Biol 122:239-250

3. Bajnath RB, van Hoeve MH, De Jonge HR, Groot JA (1992) Regulation of apical $\mathrm{Cl}^{-}$conductance and basolateral $\mathrm{K}^{+}$conductance by phorbol esters in HT-29cl.19A cells. Am J Physiol 263:C759-C766

4. Bajnath RB, van den Berghe N, De Jonge HR, Groot JA (1993) Activation of ion transport by combined effects of ionomycin, forskolin and phorbol ester on cultured HT-29cl.19A human colonocytes. Pflügers Arch 425:90-99

5. Bajnath RB, Groot JA, De Jonge HR, Kansen M, Bijman J (1993) Synergistic activation of non-rectifying small conductance chloride channels by forskolin and phorbol esters in cellattached patches of the human colon carcinoma cell line HT-29cl.19A. Pflügers Arch 425:100-108
6. Bradbury NA, Bridges RJ (1992) Endocytosis is regulated by protein kinase $\mathrm{A}$, but not protein kinase $\mathrm{C}$ in a secretory epithelial cell line. Biochem Biophys Res Commun 184:1173-1180

7. Bradbury NA, Jilling J, Berta G, Sorscher EJ, Bridges RJ, Kirk KL (1992) Regulation of plasma membrane recycling by CFTR. Science 256:530-531

8. Capparelli AW, Heng MCY, Li L, Jo OD, Yanagawa N (1993) Brefeldin A inhibits phosphate transport in opposum kidney cells. Am J Physiol 264:C40-C47

9. Denning GM, Ostedgaard LS, Cheng SH, Smith AE, Welsh MJ (1992) Localization of cystic fibrosis transmembrane conductance regulator in chloride secretory epithelia. J Clin Invest 89:339-349

10. Farack UM, Gerzer R, Keravis TM, Loeschke K (1988) Discrepancy between effects of cholera toxin on net fluid movement and cAMP levels in rat jejunum, ileum, and colon. Dig. Dis Sci 33:1153-1158

11. Fuller CM, Bridges RJ, Benos DJ (1994) Forskolin- but not ionomycin-evoked $\mathrm{Cl}^{-}$secretion in colonic epithelia depends on intact microtubules. Am J Physiol 266:C661-C668

12. Gilbert T, LeBivic A, Quaroni A, Rodriquez-Boulan E (1991) Microtubular organization and its involvement in the biogenetic pathways of plasma membrane proteins in Caco-2 intestinal epithelial cells. J Cell Biol 113:275-288

13. Huffejt ME, Blum RA, Miller SG, Hsiao-Ping, Moore H, Machen TE (1994) Regulated Cl transport, and Cl permeability, and exocytosis in T-84 cells. J Clin Invest 93:1900-1910

14. Lippincott-Schwartz J, Yuan LC, Bonifacino JS, Klausner RD (1989) Rapid distribution of Golgi-proteins into the ER in cells treated with brefeldin A: evidence for membrane recycling from the Golgi to ER. Cell 56:801-813

15. Misumi Y, Miki K, Takatsuki K, Tamura G, Ikehara Y (1986) Novel blockade by brefeldin A of intracellular transport of secretory proteins in cultured rat hepatocytes. J Biol Chem 261: 11398-11403

16. Morris AP, Cunningham SA, Tousson A, Benos DJ, Frizzell RA (1994) Polarization-dependent apical membrane CFTR targeting underlies cAMP-stimulated $\mathrm{Cl}^{-}$secretion in epithelial cells. Am J Physiol 266:C254-C268

17. Philips ME, Taylor A (1989) Effect of nocodazole on the water permeability response to vasopressin in rabbit collecting tubules perfused in vitro. J Physiol (Lond) 411:529-544

18. Philips ME, Taylor A (1992) Effect of colcemid on the water permeability response to vasopressin in isolated perfused rabbit collecting tubules. J Physiol (Lond) 456:591-608

19. Prince LS, Tousson A, Marchase RB (1993) Cell surface labeling of CFTR in T-84 cells. Am J Physiol 26:C491-C498

20. Schwiebert EM, Gesek F, Ercolani L, Wjasow C, Gruenert DC, Karlson K, Stanton BA (1994) Heterotrimeric G proteins, vesicle trafficking, and CFTR $\mathrm{Cl}^{-}$channels. Am J Physiol 267: $\mathrm{C} 272 \mathrm{C} 281$

21. Sorscher EJ, Fuller CM, Bridges RJ, Tousson A, Marchase RB, Brinkley BR, Frizzell RA, Benos DJ (1992) Identification of a membrane protein from $\mathrm{T}-84$ cells using antibodies made against a DIDS-binding peptide. Am J Physiol 262: C136-C147

22. Van den Moortele S, Picart R, Tixier-Vidal A, Tougard C (1992) Nocodazole and taxol affect subcellular compartments but not secretory activity of GH3B6 prolactin cells. Eur J Cell Biol 60:217-227 